\title{
Correction to: Glycogen Synthase Kinase-3 Inhibition Promotes Proliferation and Neuronal Differentiation of Human-Induced Pluripotent Stem Cell-Derived Neural Progenitors by Esfamdoaro F, et al. Stem Cells Dev 2011;21(17):3233-3242 DOI:10.1089/scd.2011.0678
}

The authors of the article entitled Glycogen Synthase Kinase-3 Inhibition Promotes Proliferation and Neuronal 1 Differentiation of Human-Induced Pluripotent Stem Cell-Derived Neural Progenitors published in Stem Cells Dev 2011;21(17):3233-3242 wish to correct an error.

An error related to data handling/labelling during the preparation of the neural progenitors images in Figure 1A (day 0) resulted in an incorrect figure panel placement such that the day 0 and day 1 of control data were derived from the same sample.

The original figure is below:
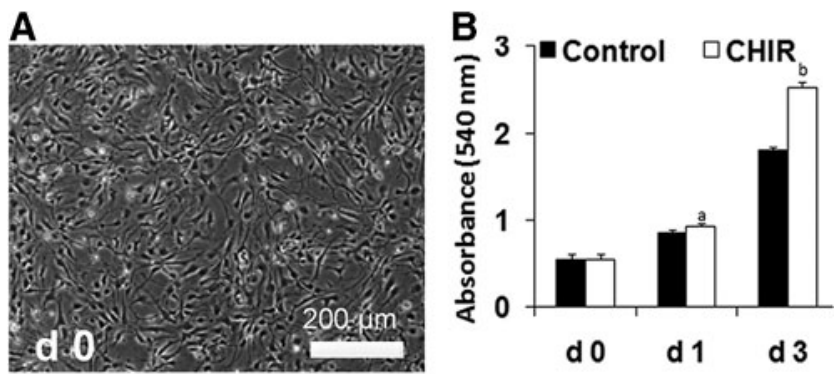

The authors have replace the "day0" image from Figure 1A with the correct image as shown below.
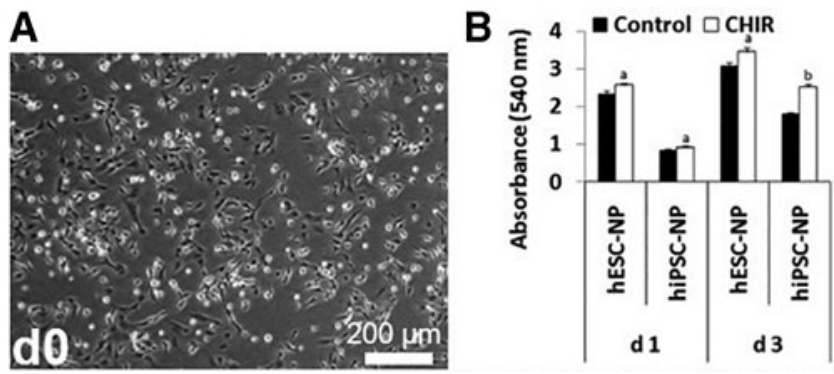

The online version of this article has been revised to reflect this correction.

The authors sincerely regret this error. 